\title{
Basal cell carcinoma of the prostate: A case report and review of the literature
}

\author{
TADAMASA SHIBUYA $^{1,2}$, GO TAKAHASHI ${ }^{1,2}$ and TOMOKO KAN ${ }^{1}$ \\ ${ }^{1}$ Department of Urology, Nankai Medical Center, Saiki, Oita 876-0857; ${ }^{2}$ Department of Urology, \\ Faculty of Medicine, Oita University, Yufu, Oita 879-5593, Japan
}

Received September 7, 2018; Accepted October 25, 2018

DOI: $10.3892 / \mathrm{mco} .2018 .1754$

\begin{abstract}
Basal cell carcinoma (BCC) of the prostate is a rare tumor exhibiting various morphological characteristics, and its progression varies from an indolent to an aggressive type, with local recurrence or distant metastasis. We herein report the case of a patient who was diagnosed with early-stage BCC of the prostate and treated by surgery. A 68 year-old-man visited our hospital for a follow-up for bladder cancer. In August 2017, his serum prostate-specific-antigen (PSA) level was measured to be $5.61 \mathrm{ng} / \mathrm{ml}$ and prostate biopsy was performed. Histological examination revealed BCC of the prostate, with immunostaining examination of tumor cells showing positive results for p63 but negative results for PSA. Imaging examination showed no metastasis. Retropubic radical prostatectomy with extended lymph node dissection was performed. Pathological examination of the surgical specimen revealed coexistence of a predominant basaloid component and an adenoid cystic-like tumor with cribriform appearance. There was no extracapsular infiltration or lymph node metastasis. The patient remained alive and recurrence-free after 1 year of follow-up.
\end{abstract}

\section{Introduction}

The glandular tissue of the prostate includes secretory cells on the side facing the glandular cavity and basal cells on the basal side. The proliferation of basal cells in the prostate varies from hyperplasia to carcinoma, but carcinoma arising from the basal cells of the prostate is extremely rare (1). Basal cell carcinoma (BCC) of the prostate has been considered as a tumor with low malignant potential in a limited number of clinical studies; however, it has been reported that this tumor has an aggressive potential that causes metastasis and recurrence (2). We herein

Correspondence to: Dr Tadamasa Shibuya, Department of Urology, Faculty of Medicine, Oita University, 1-1 Idaigaoka, Hasama-machi, Yufu, Oita 879-5593, Japan

E-mail: tadamasa@oita-u.ac.jp

Key words: basal cell carcinoma of the prostate, radical prostatectomy report a case of BCC of the prostate that was diagnosed at an early stage and was treated by radical surgical resection.

\section{Case report}

A 68 year-old-man visited the Department of Urology, Nankai Medical Center (Saiki, Japan) in August 2017 for a periodic follow-up examination for bladder cancer. The patient had been diagnosed with bladder cancer and had undergone transurethral resection of the bladder tumor in March 2016. Pathological examination revealed a high-grade urothelial carcinoma in situ (CIS). Intravesical Bacillus Calmette-Guérin therapy was administered for CIS of the bladder, after which time no recurrence of the bladder cancer was observed. Although the prostate-specific-antigen (PSA) level was normal prior to August 2017, the PSA level measured in August 2017 had increased to $5.61 \mathrm{ng} / \mathrm{ml}$ (PSA normal range, $\leq 4.0 \mathrm{ng} / \mathrm{ml}$ ). Prostate biopsy was performed and histological examination revealed tumor cells with a high nucleus-to-cytoplasm ratio forming a small nest-like basaloid cell carcinoma in a small part of the biopsy specimen (Fig. 1A). A peripheral palisading pattern was also observed (Fig. 1B). The results of immunostaining examination revealed that the tumor cells tested positive for p63 (Fig. 1C), but negative for PSA (Fig. 1D). Based on the abovementioned results, the patients was diagnosed with $\mathrm{BCC}$ of the prostate. Magnetic resonance imaging did not reveal any obvious abnormal lesion in the prostate (Fig. 2). Computed tomography and bone scintigraphy showed no metastatic lesions. After confirming that there was no recurrence of the bladder cancer by random biopsy, retropubic radical prostatectomy with extended lymph node dissection was performed. Pathological examination of the surgical specimen revealed a predominant basaloid component admixed with an adenoid cystic-like tumor with cribriform appearance (Fig. 3A and B). The resection margin was negative and there were no lymph node metastases. The patient was examined via CT scan every 3 months until the last follow up on August 15th 2018. The individual remained alive and recurrence-free 1 year after surgery.

\section{Discussion}

$\mathrm{BCC}$ of the prostate is morphologically diverse and may be considered as an adenoid cystic carcinoma, which is 
A

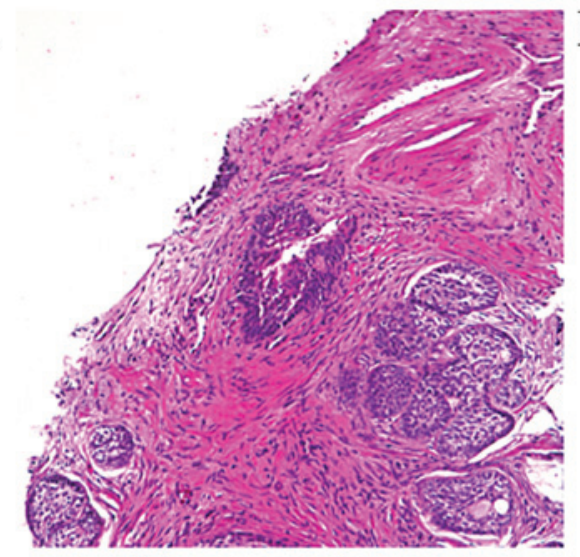

C

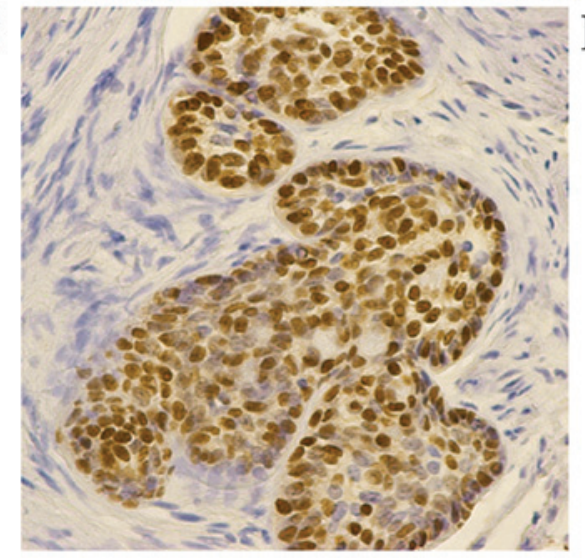

B

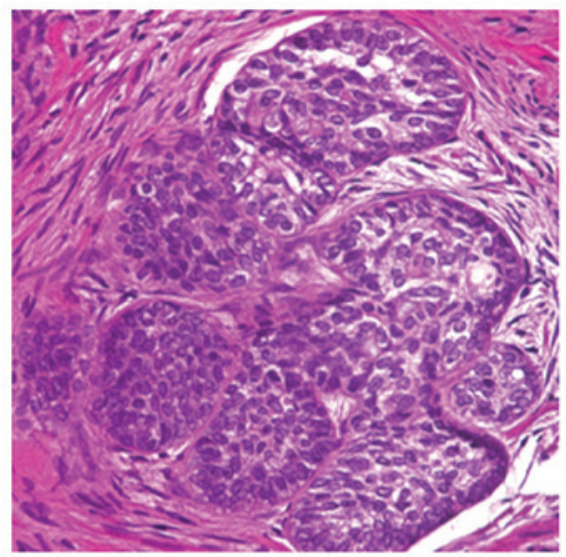

D

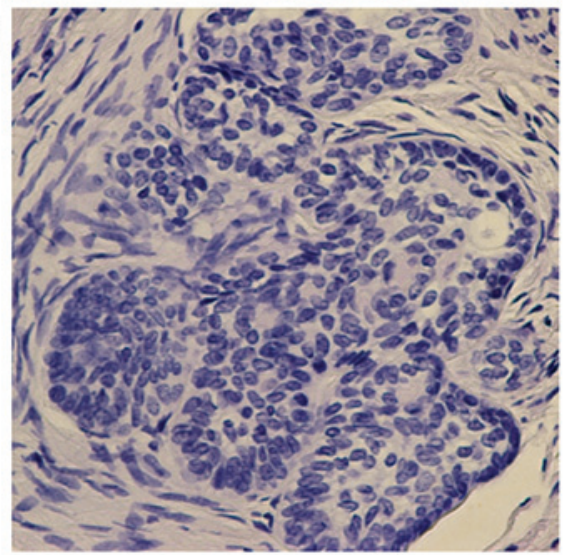

Figure 1. Histological examination of hematoxylin and eosin-stained sections of the biopsy specimen of the prostate showing (A) small nests of the basaloid component in a small part of the specimen (magnification, $\mathrm{x} 40$ ) and (B) neoplastic cells with round nuclei and scant cytoplasm forming small nests with a peripheral palisading pattern (magnification, x200). Immunostaining of the biopsy specimen of the prostate showing the neoplastic cells were (C) positive for p63 and (D) negative for prostate-specific antigen (magnification for each, x200).

histologically similar to a salivary gland tumor; it may also be classified as a basaloid cell carcinoma, which is histologically similar to a basal cell carcinoma of the skin $(3,4)$. Some cases have been reported to comprise a single tissue type, namely basaloid cell carcinoma or adenoid cystic carcinoma; however, cases have been reported where these two types coexist within the same tumor. In a clinicopathological study of 29 cases of BCC of the prostate, Ali and Epstein reported that small, solid, nest-like tumors with peripheral palisading and adenoid cysticlike tumors were the most common pattern (5). In the present case, small basaloid nests and adenoid cystic-like tumor were also observed, which is considered to be similar to the tissue pattern previously reported (5).

$\mathrm{BCC}$ of the prostate is a rare tumor; upon searching the PubMed electronic database, only 98 reported cases of BCC of the prostate were retrieved. When summarizing the 75 cases that were available (6-13), the mean patient age was $65.3 \pm 13.6$ years, and the mean observation period was $41.8 \pm 44.8$ months. This type of cancer was most common among elderly men (age range, 65-84 years) and the chief complaint of several patients was urinary obstruction. Radical prostatectomy was performed in 26 of the 75 patients; among those, 16 patients were alive without cancer recurrence at the time of reporting these cases. In the remaining 10 patients, radical prostatectomy was not curative. Some patients only underwent transurethral resection of prostate, which is not a curative option for prostate cancer, and achieved long-term survival without recurrence. Of the

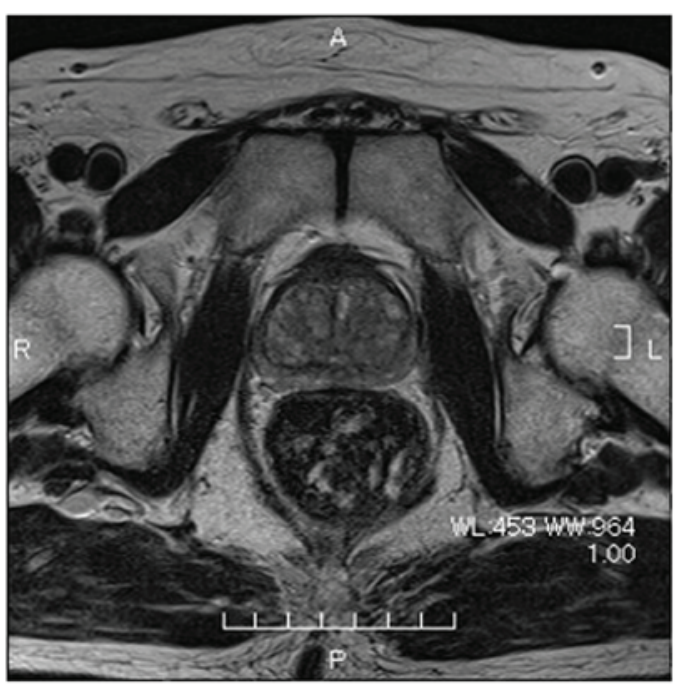

Figure 2. Axial magnetic resonance imaging-T2 weighted image showing absence of an obvious mass lesion of the prostate.

75 patients, 28 (37\%) developed disease progression, such as metastasis and recurrence, and eventually succumbed to the disease. BCC of the prostate may present as an indolent tumor that allows long-term survival with non-curative treatment, such as transurethral resection of the prostate alone; however, it may also present as an aggressive tumor prone to metastasis 

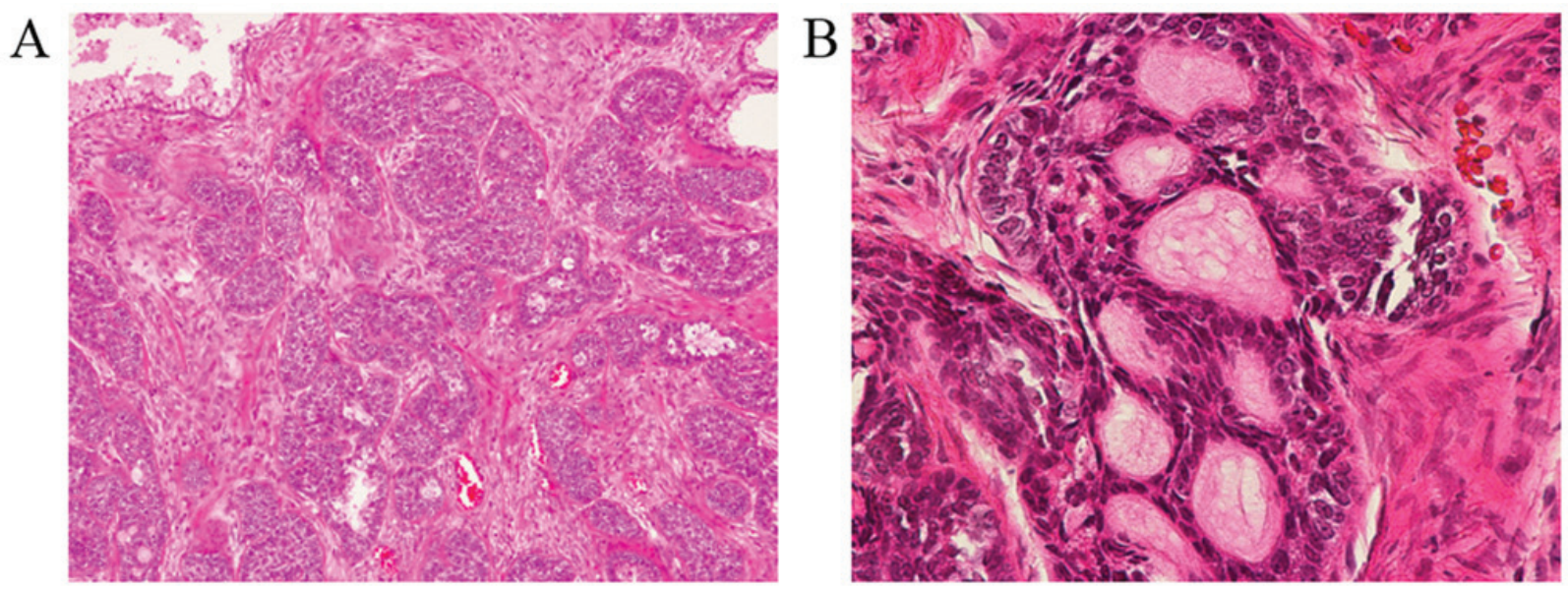

Figure 3. (A) Examination of the surgical specimen of the prostate revealed a carcinoma with a predominant basaloid cell component and (B) an adenoid cystic-like tumor with cribriform appearance. Hematoxylin and eosin staining; magnification, (A) x40 and (B) x200.

or recurrence. It is impossible to determine whether $\mathrm{BCC}$ of the prostate is of the indolent or aggressive type at the time of early-stage diagnosis; however, some reports suggest that a predominant basaloid component may be associated with a poor prognosis $(6,14)$.

According to the previous literature, radiation therapy, chemotherapy and hormone therapy have been included in the treatment in addition to surgery. Tuan et al reported the only case of BCC of the prostate where complete remission was achieved by a combination of chemotherapy and radiotherapy (9), but the efficacy of these treatment options has not yet been established. Therefore, due to the possibility of an aggressive tumor and the lack of effective treatment options, radical surgery should be considered if $\mathrm{BCC}$ of the prostate is diagnosed at an early stage and a basaloid component is detected. In the present case, the possibility of an aggressive potential could not be excluded, as a basaloid component was detected in the biopsy specimen and imaging examination revealed that the $\mathrm{BCC}$ was confined to the prostate; therefore, retropubic radical prostatectomy was selected as the treatment. An adenoid cystic-like tumor component was also identified in the surgical specimen, but the basaloid component was predominant. These pathological findings suggested the possibility of a poor prognosis if curative treatment was not selected.

Invasion of the bladder cancer cells into the prostate was included in the differential diagnosis of BCC of the prostate (15). Since this patient had a history of CIS of the bladder, immunostaining of the biopsy specimen was performed. The results of immunostaining demonstrated that the tumor cells tested negative for cytokeratin (CK)7 and CK20, which are usually expressed in urothelial carcinoma cells (16). Furthermore, random biopsy was performed, and it was confirmed that CIS of the bladder had not recurred. The absence of immunoreactivity with antibodies against CK7 and CK20 and the results of the random biopsy of the bladder confirmed that the CIS of the bladder had not invaded the prostate.

BCC of the prostate is a rare tumor and an optimal treatment has not yet been established. The present case report and a review of the relevant literature suggest that radical surgery must be considered if $\mathrm{BCC}$ of the prostate is diagnosed at an early stage due to its aggressive potential, particularly if it includes a predominant basaloid component.

\section{Acknowledgements}

Not applicable.

\section{Funding}

No funding was received.

\section{Authors' contributions}

GT and TK were part of the treatment team for the patient. TS was the attending physician and surgeon of the patient and was the first author of the manuscript.

\section{Ethics approval and consent to participate}

Not applicable.

\section{Availability of data and materials}

Not applicable.

\section{Consent for publication}

The patient provided written informed consent to the publication of the case details and any associated images.

\section{Competing interests}

The authors declare that they have no competing interests.

\section{References}

1. McKenney JK, Amin MB, Srigley JR, Jimenez RE, Ro JY, Grignon DJ and Young RH: Basal cell proliferations of the prostate other than usual basal cell hyperplasia: A clinicopathologic study of 23 cases, including four carcinomas, with a proposed classification. Am J Surg Pathol 28: 1289-1298, 2004. 
2. Iczkowski KA, Ferguson KL, Grier DD, Hossain D, Banerjee SS McNeal JE and Bostwick DG: Adenoid cystic/basal cell carcinoma of the prostate: Clinicopathologic findings in 19 cases. Am J Surg Pathol 27: 1523-1529, 2003.

3. Ayyathurai R, Civantos F, Soloway MS and Manoharan M: Basal cell carcinoma of the prostate: Current concepts. BJU Int 99: 1345-1349, 2007.

4. Begnami MD, Quezado M, Pinto P, Linehan WM and Merino M: Adenoid cystic/basal cell carcinoma of the prostate: Review and update. Arch Pathol Lab Med 131: 637-640, 2007.

5. Ali TZ and Epstein JI: Basal cell carcinoma of the prostate: A clinicopathologic study of 29 cases. Am J Surg Pathol 31: 697-705, 2007.

6. Komura K, Inamoto T, Tsuji M, Ibuki N, Koyama K, Ubai T, Azuma $\mathrm{H}$ and Katsuoka Y: Basal cell carcinoma of the prostate: Unusual subtype of prostatic carcinoma. Int J Clin Oncol 15: 594-600, 2010

7. Bohn OL, Rios-Luna NP, Navarro L, Duran-Peña A and Sanchez-Sosa S: Basal cell carcinoma of the prostate gland: A case report and brief review of the basal cell proliferations of the prostate gland. Ann Diagn Pathol 14: 365-368, 2010.

8. Ahuja A, Das P, Kumar N, Saini AK, Seth A and Ray R: Adenoid cystic carcinoma of the prostate: Case report on a rare entity and review of the literature. Pathol Res Pract 207: 391-394, 2011.

9. Tuan J, Pandha H, Corbishley C and Khoo V: Basaloid carcinoma of the prostate: A literature review with case report. Indian J Urol 28: 322-324, 2012.
10. Stearns G, Cheng JS, Shapiro O and Nsouli I: Basal cell carcinoma of the prostate: A case report. Urology 79: e79-e80, 2012.

11. Chang K, Dai B, Kong Y, Qu Y, Wu J, Ye D, Yao X, Zhang S, Zhang H, Zhu Y, et al: Basal cell carcinoma of the prostate: Clinicopathologic analysis of three cases and a review of the literature. World J Surg Oncol 11: 193, 2013.

12. Tsuruta K, Funahashi Y and Kato M: Basal cell carcinoma arising in the prostate. Int J Urol 21: 1072-1073, 2014.

13. Simper NB, Jones CL, MacLennan GT, Montironi R, Williamson SR, Osunkoya AO, Wang M, Zhang S, Grignon DJ, Eble JN, et al: Basal cell carcinoma of the prostate is an aggressive tumor with frequent loss of PTEN expression and overexpression of EGFR. Hum Pathol 46: 805-812, 2015.

14. Hudson E, Rashid M, Carter AC and Lester JF: Basaloid carcinoma of the prostate: A case report and review of the literature. Eur J Cancer Care (Engl) 17: 509-511, 2008.

15. Segawa N, Tsuji M, Nishida T, Takahara K, Azuma H and Katsuoka Y: Basal cell carcinoma of the prostate: Report of a case and review of the published reports. Int J Urol 15: 557-559, 2008.

16. Bassily NH, Vallorosi CJ, Akdas G, Montie JE and Rubin MA: Coordinate expression of cytokeratins 7 and 20 in prostate adenocarcinoma and bladder urothelial carcinoma. Am J Clin Pathol 113: 383-388, 2000. 